\title{
Transfer in the A-B, C-B paradigm as a function of stimulus class'
}

KATIE OLIVIER AND DONALD H. KAUSLER

SAINT LOUIS UNIVERSITY
The effect of the relationship between the form-classes of the stimulus components in the A-B, C-B transfer paradigm was investigated. Relative to the $A-B, C-D$ paradigm, significant negative transfer was found when $A$ and $C$ were from the same class (both nonsense syllables). When $A$ and $C$ were from different classes (adjectives or geometric figures and nonsense syllables), less negative transfer occurred. The results were interpreted in terms of R-S interference as a source of negative transfer in the $C-B$ paradigm, with the degree of interference being a function of the similarity between the form-classes of the stimuli for the two lists.

With response components of high meaningfulness, the A-B, C-B paired-associate transfer paradigm typically yields negative transfer relative to the A-B, C-D control (cf. Martin, 1965). Presumably, negative transfer stems from the fact that the $\mathrm{R}-\mathrm{S}$ associations of the two lists (B-A and B-C) enter into an A-B, A-C, or interference, relationship. For $S-R$ transfer, the A-B, A-C relationship most likely generates negative effects through competition between the responses of the two lists and the unlearning of List 1 responses and associations (Barnes \& Underwood, 1959). R-S competition and the unlearning of $B-A$ associations in the $A-B$, $C-B$ paradigm conceivably generate comparable $R-S$ interference, and this interference exerts a concomitant interference on S-R acquisition of List 2 , thus accounting for the resultant $S-R$ negative transfer (Martin, 1965). Evidence for B-A unlearning in the C-B paradigm was recently given by Ellington \& Kausler (1965).

Postman, Keppel, \& Stark (1965) found that S-R negative transfer in the $A-B, A-C$ paradigm is reduced when the $B$ and $C$ response components are from different form-classes (e.g., adjectives and letters) relative to the case where they are from the same class (e.g., both adjectives). The results of Postman et al (1965) may be explained by postulating a decrease in the elicitation of List 1 associations during List 2 practice, and an accompanying diminution of interference, when the responses are from different classes. In view of the functional equivalence to the A-B, A-C paradigm described above, a comparable effect may be expected in the A-B, C-B paradigm. That is, $S-R$ negative transfer for $C-B$ pairs should be less when the $A$ and $C$ (stimulus) components are from different form-classes than when they are from the same class. This hypothesis follows from an expected decrease in R-S competition and unlearning as the stimulus class changes. Method

Sixty undergraduate Ss were assigned alternately to four transfer groups, three experimental (Groups E1,
$\mathrm{E} 2$, and E3) representing variations via stimulus formclass of the A-B, C-B paradigm and one control (Group C) representing the standard $A-B, C-D$ control paradigm. All four groups received the same List 2 consisting of nonsense syllables as stimulus and adjectives as response components. Form-class and paradigmatic variations were manipulated by means of List 1 content. For Group E1 the stimuli of List 1 were, as in List 2, nonsense syllables (List 1 responses were, of course, identical to those of List 2); for Groups E2 and E3 the stimuli were adjectives and geometric figures, respectively. The stimuli and responses of List 1 for Group $\mathrm{C}$ were nonsense syllables and adjectives, respectively, that were unrelated in content to their List 2 counterparts.

All of the nonsense syllables were of high (80-100\%) association value (Archer, 1960). The adjectives were those employed earlier by Kausler \& Kanoti (1963), and the geometric figures were selected from Gibson's (1941) standard stimuli. Interlist and intralist similarity between components was minimized as much as possible. Each list contained eight pairs arranged in three different orders to control for serial effects. Following three trials on a warm-up list of three pairs, List 1 was practiced to a criterion of one perfect trial. List 2 was then presented for 10 trials. Practice on all lists was by the anticipation method, with the materials exposed on a memory drum at a 2:2-sec. rate and a 4-sec. intertrial interval.

\section{Results}

Summary data for trials to criterion on List 1 and the number of correct responses (CRs) on List 2 are given in Table 1. A Bartlett's test and an analysis of variance revealed that the four groups differed significantly on List 1 in both variability $\left(x^{2}=28.20 ; \mathrm{df}=3\right.$; $\mathrm{p}<.001)$ and means $(\mathrm{F}=6.72 ; \mathrm{df}=3 / 56 ; \mathrm{p}<.01)$.

The hypothesis investigated in this study implies that Group E1 should display an interference effect on List 2, relative to Group C, and that Groups E2 and E3 should

Table 1.

Summary Data for List 1 Trials and List 2 Correct Responses

\begin{tabular}{lcccc} 
Condition & \multicolumn{2}{c}{$\begin{array}{c}\text { List } \\
\text { Trials }\end{array}$} & \multicolumn{2}{c}{$\begin{array}{c}\text { List 2 } \\
\end{array}$} \\
\cline { 2 - 5 } & Mean & SD & Mean & SD \\
\hline Group C & 12.20 & 5.88 & 55.20 & 9.63 \\
Group E 1 & 15.27 & 8.75 & 44.13 & 14.75 \\
Group E2 & 10.33 & 8.75 & 50.73 & 9.78 \\
Group E3 & 6.00 & 1.73 & 49.73 & 13.18 \\
\hline
\end{tabular}


display considerably less interference. An inspection of the mean CRs (Table 1) reveals that the groups are ordered in this direction. That is, negative transfer is evident for all three experimental groups, and the amount is greatest in Group E1. However, an analysis of variance (with homogeneity of variance) did not yield a significant between-group effect ( $F=2.14$; $\mathrm{df}=3 / 56 ; \mathrm{p}>.05)$. Perhaps a more adequate test of this hypothesis rests in the orthogonal comparison of Group E1 versus the other three groups. This analysis yielded a significant comparison $(F=4.67 ; \mathrm{df}=1 / 56 ; \mathrm{p}<.05)$. In addition, a Duncan's multiple range test revealed a significant difference between Groups $\mathrm{C}$ and E1, with none of the other comparisons approaching significance. Thus the $\mathrm{R}-\mathrm{S}$ interference and accompanying S-R negative transfer that is generated when $A$ and $C$ are from the same class seems to dissipate when $A$ and $C$ are from different classes.

\section{Discussion}

Several methodological problems necessarily restrict the dissipation of $\mathrm{R}-\mathrm{S}$ interference interpretation given above. The question may be raised concerning the adequacy of the $\mathrm{C}$ concition to serve as a base, in terms of nonspecific transfer effects, for evaluating the specific transfer effects of Groups E2 and E3. General habits contributing to nonspecific transfer are ones that are acquired during List 1 practice. If the stimulus class remains the same on List 2 , then the habits acquired through exposure to other members of that class in List 1 should transfer to List 2. Thus stimulus-related nonspecific transfer should be comparable for Groups $\mathrm{C}$ and $\mathrm{E} 1$ in that nonsense syllables served as stimuli for both groups. For Groups E2 and E3 the change in stimulus class conceivably reduces the amount of nonspecific transfer from List 1 to List 2. However, this reduction should, if anything, depress the number of CRs made by Groups E2 and E3 and thereby spuriously lower specific transfer effects manifested in these two groups. In other words, the disparity between Group E1 and Groups E2 and E3 is likely to be underestimated, whereas the disparity between Group $\mathrm{C}$ and Groups E2 and E3 is likely to be overestimated in the present study.

A second problem rests in the overlapping letter content between interlist stimulus components that inevitably occurs when a large number of nonsense syllables are employed. Although overlapping was minimized as much as possible, the possibility remains that the amount of interlist similarity present in Groups $C$ and $E 1$ was large enough to alter the $A-B, C-D$ and $A-B, C-B$ paradigmatic relationships assumed operative in these groups. Mitigating this possibility, however, is the apparent tendency of Ss to employ all, or nearly all; of the letter content as the functional stimulus when a high meaningful nonsense syllable serves as a nominal stimulus (Leicht \& Kausler, 1965). Interlist commonality of stimulus letter content does not necessarily imply commonality of functional stimuli.

A third problem concerns the presence of differential rates of acquisition on List 1. Although the groups were taken to the same criterion of mastery, differential rates imply that the groups may not have been equated in degree of List 1 learning prior to List 2 practice. Several recent studies (e.g., Dean \& Kausler, 1964) have reported a relationship between degree of List 1 learning and the direction and amount of transfer in the $\mathrm{C}-\mathrm{B}$ paradigm. However, in this study the significant difference in rate of List 1 learning was attributable solely to Group E3. Both Duncan's multiple range tests and separate t-tests (with specific group error variances) revealed that the mean number of trials for Group E3 was significantly less $(p<.01)$ than that for each of the other groups. No other comparison between means approached significance. When Group E3 is omitted from the analyses, the between-group effect for List 1 falls short of significance $(F=2.13 ; d f=2 / 42 ; p>.10)$, but the between-group effect for List 2 reaches significance $(F=3.44 ; \mathrm{df}=2 / 42 ; \mathrm{p}<.05)$. Moreover, the comparison between Groups $\mathrm{C}$ and E1 remains significant, and the other two comparisons continue to fall short of significance. Finally, a correlation coefficient between number of trials on List 1 and CRs on List 2 was computed for each of the four groups. None of these coefficients approached significance (all ps > .10).

\section{References}

Archer, E. J. A re-evaluation of the meaningfulness of all possible CVC trigrams. Psychol. Monogr., 1960, 74, No. 10 (Whole No. 497).

Barnes, J. M., \& Underwood, B. J. "Fate" of first-list associations in transfer theory. J. exp. Psychol., 1959, 58, 97-105.

Dean, M. G., \& Kausler, D. H. Degree of first-list learning and and stimulus meaningfulness as related to transfer in the $A-B$, C-B paradigm. J. verbal Learn. verbal Behav., 1964, 3, 330-334.

Ellington, N. R., \& Kausler, D. H. Supplementary report: "Fate" of List $1 \mathrm{R}-\mathrm{S}$ associations in transfer theory. J. exp. Psychol., 1965, 69, 207-208.

Gibson, E. J. Retroactive inhibition as a function of degree of generalization between tasks. J. exp. Psychol., 1941, 28, 93115 .

Kausler, D. H., \& Kanoti, G. A. R-S learning and negative transfer effects with a mixed list. $J$. exp. Psychol., 1963, 65, 201-205.

Leicht, K. L., \& Kausler, D. H. Supplementary report: Functional stimulus learning as related to degree of practice and meaningfulness. J. exp. Psychol., 1965, 69, 100-101.

Martin, E. Transfer of verbal paired associates. Psychol. Rev. $1965,72,327-343$.

Postman, L., Keppel, G., \& Stark, K. Unlearning as a function of the relationship between successive response classes. $J$. exp. Psychol., 1965, 69, 111-118.

\section{Note}

1. This study is based on a thesis submitted by the first author to the Graduate School, St. Louis University, in partial fulfillment of the requirements for the Master of Science degree. 